\title{
Funny or distasteful? A cross-cultural perspective on surprise and humour in multimodal advertising
}

\author{
Anna Stwora \\ University of Silesia, Poland \& Sapienza University of Rome, Italy \\ anna stwora@interia.eu
}

\begin{abstract}
Today's infotainment clutter puts pressure on advertisers to come up with more surprising and more memorable ads. This need for novelty, creativity, and astonishment does set the expectation bar high, steering ads towards various means of eliciting surprise, including humour, shock, and taboo. In this paper, the author will try to investigate a set of multimodal advertising messages which use (debatable) humour and surprise, with a view to finding trans-cultural similarities and differences in terms of ad appreciation. The primary objective of this paper is to explore attitudinal responses of Taiwanese informants to controversial humorous advertisements in English; to this end, an online survey was conducted to ask them about their interpretations of and feelings towards a selection of ads. Its results will be compared with those obtained from Polish respondents, described in the author's previous study (Stwora 2020).
\end{abstract}

Keywords: multimodal advertising discourse, ad appreciation, cross-cultural humour, comparative studies.

\section{Introduction}

Contemporary research into humour in language is no longer confined to the verbal dimension, for we all witness "a progressive broadening of corpora to include audiovisual data and multimodal analyses" (Attardo 2017). Humour in advertising, however, seems a particularly slippery topic because the very phenomenon of humour is simultaneously universal, individualised, and culture-specific, which sometimes makes it difficult for advertising agencies to produce balanced ads which are neither boring nor overdone.

Today's infotainment ${ }^{1}$ clutter puts pressure on advertisers to come up with more surprising and more memorable ads. This need for novelty, creativity, and astonishment does set the expectation bar high, steering the ads towards various means of eliciting surprise,

\footnotetext{
${ }^{1}$ Understood as the action of providing (or being provided with) any "material which is intended both to entertain and to inform" (Oxford Dictionaries online).
} 
including humour, shock, and taboo. These, however, may be viewed as either appealing or appalling because the very perception of humour is dependent on many socio-cultural factors, including the perceiver's age, ethnicity, gender or culture. In an attempt to draw the line between what is conceived as funny and what may be seen as distasteful, the author will try to investigate a set of multimodal advertising messages that use (debatable) humour and surprise with a view to finding trans-cultural similarities and differences in terms of ad appreciation.

The primary objective of this paper is to explore attitudinal responses of Taiwanese informants to controversial humorous advertisements in English; to this end, an online survey was conducted to ask them about their interpretations of and feelings towards a selection of ads. Its results will be compared with those obtained from Polish respondents, described in the author's previous study (Stwora 2020).

\section{Eliciting surprise through advertising}

As already signalled in the introduction, advertising agencies often rely on the power of more or less humorous surprise and on the feeling of shock or astonishment caused by an unexpected or incongruous element of the message. In order to make it possible for the reader to fully grasp the workings of humour in controversial humorous ads, this section will briefly outline the topics of humour in multimodal advertising, of shock and taboo in ads, as well as of failed humour.

\subsection{Humour in multimodal ads}

First, it is imperative to explain the very term multimodality; it is defined as the application of several different yet equally important and meaningful modes of communication (cf. Bateman 2008; Kress 2010, 2012) or as the complex dialogical interplay between the verbal and the visual layer in advertising (Karaśkiewicz 2013). In general, advertisements are treated as multimodal pieces of information, which make use of an inventory of equally important (Bateman 2008) and semantically related visual and lexical items that cannot be viewed separately because the final meaning is constructed on the basis of both the textual and the pictorial.

As far as the multimodal means for producing humour are concerned, one can distinguish three possible options:

(a) the picture can be an illustration of the verbal joke, without adding to the humorous effect; hence, only the text is responsible for the humorous effect,

(b) the picture provides supporting information not contained in the humorous text; hence, both text and image contribute to the humorous effect,

(c) the picture is essential for the production of humour; hence, humour is based only on the picture, not on the text, if any.

(Samson \& Huber 2007: 14)

What renders humour funny, however, is that it rests on the surprising incongruity between the things, forms or concepts involved, on "a comic collision of or oscillation between two frames of reference / worlds of discourse / codes / associative contexts" (Krikmann 2009: 17). One of the theoretical cornerstones of the said theory, known as the incongruity-resolution theory of humour, is the concept of incongruity which usually involves two opposites that, nonetheless, need to share some similar features that would constitute their common ground. "The boundaries between opposing scripts are temporarily blurred until they are realised; the tension between these boundaries that is then released (...)" (Kyratzis 2003: 2) is what causes 
humour, for the perceivers "must make a connection between two realities in order to resolve the incongruence" (Pérez-Sobrino 2017: 128), to find the connection between seemingly mismatched elements of discourse, and to make sense of it.

They are surprised, Hurley et al. (2011) argue, by what they have expected not to happen, nurturing expectations about something else instead. With the violated expectations claim refuted, it may be concluded that what surprises people is what they have not expected to happen and what is hence unexpected (whether or not holding alterative expectations which are thus indeed violated) and, simultaneously, what cannot be effortlessly assimilated. Humour displays surprising novelty and originality, suddenly catching the hearer off guard with something that they cannot smoothly assimilate (Morreall 1983).

(Dynel 2013: 27)

Nonetheless, it is important to note that while incongruity is surprising, it differs from shock in that the latter is upsetting an experience, whereas the former is meant to be pleasurable and cognitively stimulating.

\subsection{Shock and taboo in ads}

Without getting into too many details, shock in ads is founded upon "unusual combinations of elements in odd scenarios in order to attract audiences to a certain brand or to bring awareness to a certain public service issue, health issue, or cause" (Pérez-Sobrino 2016: 257). Such advertisements "are granted a special license to shock, to achieve a truly disturbing effect" (Simões \& Freitas 2008: 201). This is often achieved by, for example, the use of disturbing images or words, or by flouting deep-seated taboos, that is, proscriptive behaviours for specific communities and contexts at a given place and time (Allan \& Burridge 2006: 27) or, more generally, "(...) 'something that should not be touched' - whether because of disgust or awe" (Simões \& Freitas 2008: 1). In his article on cross-linguistic universalities in taboos and swearing, Matusz (2017), after Bussmann (1998), says that the term taboo comes from the Polynesian tabu, which means the "consecrated" or "inviolable" (Bussmann 1998: 475). He cites the following categories of common human taboos, as outlined by Allan \& Burridge (2006):

1. Bodies and their effluvia (sweat, snot, faeces, menstrual fluid, etc.).

2. The organs and acts of sex, micturition, and defecation.

3. Disease, death, and killing (including hunting and fishing).

4. Naming, addressing, touching, and viewing persons and sacred beings, objects, and places.

5. Food gathering, preparation, and consumption.

(Allan \& Burridge 2006: 1)

In the light of the foregoing, one can conclude that the inviolable generates motivation for individual, social, and cultural restrictions. Consecrated taboos, introduced by religion, draw the borderline between the holy and the profane. "One still feels, nowadays, that taboo is a ponderous and serious matter, due to its connection with the sacred" (Simões \& Freitas 2008: 197). Also, having received stigmatization from religious teachings, sex is usually considered an impure act of transgression, which implies tabooness too (Mohr 2013). Yet the most universal area of taboo is connected with various sorts of contagion; such taboos as bodily effluvia, contaminated food or decay, for instance, are elicitors of disgust because they imply danger. "The standard scientific view of disgust pictures it as a relatively primitive response that probably first evolved as a means of protection from disease and food toxins" (Korsmeyer 2008: 372). In this respect, taboos serve as visceral warning signs that repel people (for an 
interesting discussion on judgments and categorisations arising from gut feelings, see Haidt 2013).

While disgust is a universal human feeling, certain taboos may vary across cultures. Matusz stresses that "there are some interesting individual characteristics across cultures, which pertain to the presence and strength of particular taboos" (Matusz 2017: 33); he also lays great emphasis on the fact that knowing the possible scope of common human taboos can develop one's sensitivity towards intercultural similarities in this respect (Matusz 2017).

Given the fundamental link between taboo and disgust, it seems pertinent to mention the link between disgust and humour as well. What they have in common is that both (1) may be seen as reactions towards particular triggers and (2) assume some kind of violation of norms (Jajszczok 2019). Nevertheless, while humorous violation is benign, as it is associated with harmless playfulness, disgust entails threat to health or normality (Jajszczok 2019). A given trigger may perform the function of humour or disgust elicitor, but when it produces both at the same time, mixed feelings of amusement and disgust are evoked; these are naturally more intense in the observer than in the participant condition (Hemenover \& Schimmack 2007: 1102 ), as it is the case in advertising.

Humour can mitigate "the perception of tabooness and the feelings of aggression and apprehension inherent in a taboo appeal, while enhancing attention, storage of the taboo word or image in the memory, and a positive attitude toward the advertisement" (Sabri 2012: 407). That is why, in order to catch consumers' attention more effectively, advertising agencies reach for both taboo and humour: for the former to arouse the audience by means of a powerful message and for the latter to "smoothen up the negative reaction" (Yus 2016: 302) that may be triggered by the violation of the inviolable.

Naturally, individual reactions are bound to differ to some extent, as "the role of personality-dependent tolerance for ambiguity (conservatism, sensation seeking, need for cognition) [can be seen] as a predictor of appreciation for humour structure" (Staley \& Derks 1995: 97). It seems worth noting here that Davies (2008) maintains that humour per se "(...) does not give offence; its recipients take offence" (Davies 2008: 6). As a result, it is suggested that humour itself "(...) cannot be blamed, for example, for promoting racist, sexist, or other discriminatory views, although it may exploit them to make people laugh" (Tsakona 2017: 179). However, that is not to say that, as a tool, humour cannot be used to convey defamatory or discriminatory content. At this point, it should also be stated that people who get and appreciate derogatory humour do not necessarily support the idea behind it. One can laugh at witty wordplay in a racist joke without actually being racist. Likewise, one can appreciate the twist in a sexist ad without hating the opposite gender.

When applied in advertising, various taboos that exist more or less consciously in the minds of the audience can be played upon and exploited, but their success depends on the way in which the message is structured. On the one hand, if used skilfully, taboo and humour as advertising strategies can help the ad stand out from the infotainment clutter in a sophisticated manner; on the other, too explicit a message containing a strong taboo charge can render the message clumsy, weird or even offensive, thus potentially tarnishing brand image.

\subsection{Failed humour}

Speaking of negative outcomes, "the decision to opt for humorous advertising is not one to be taken lightly since it can so easily backfire" (Barsoux 1993: 138). Bold advertising can capitalise on surprise, appealing visuals or taboo topics which are exciting to the audience. But one has to remember that there are boundaries between what is attractive and what becomes distasteful or disturbing to the perceiver. "These ads can carry the viewer right to the edge of bad taste - sexual innuendo, physical or psychological violence, implications of nudity or 
partial nudity - but they should not go over the line" (Hilliard 2014: 90). Which is difficult, indeed, especially when one deals with a multicultural audience that differs in their appreciation of humour and the people or things to be laughed at.

The potentially offensive nature of humour in advertising was extensively explored by Gulas \& Weinberger (2006), as well as in Stwora \& Zemełka (2020). For the purpose of this paper, let it be just said that humour can fail for discursive or sociocultural reasons, due to deficits in linguistic capital, one's mood or disposition, different systems of values and beliefs, or simply because of a mismatch between the repertoire and the audience (Palmer 2004: 161), to name but a few. The audience may not like the use of humour coupled with taboo topics because they may consider such a strategy too controversial or offensive; sometimes, "failed humour can be explained by communicative gaps, at either the semantic or pragmatic levels" (Hale 2018: 36). But, commonly, people resist humour once they experience conflicting emotions, for example when disgust, anxiety, hostility, perplexity or other powerful yet negative emotions make it impossible to appreciate (or even see) the humour value.

Having established that a taboo tells people which topics "should not be touched' whether because of disgust or awe" (Simões \& Freitas 2008: 1), it seems clear that it is bound to influence one's perception and appreciation of humour. Different people, cultures, groups, genders, etc. have "different notions of what good and bad humour is (...), they have different stylistic criteria and standards, and different ideas of what humour is, or should 'do.' This may lead to different evaluations of the same humorous utterances and genres" (Kuipers 2009: 220), including advertising messages.

When humour creates these demarcations of what is acceptable under prevailing communicative practice, it provokes what are referred to as "symbolic boundaries, social boundaries that become salient, meaningful, and often imbued with status differences" (Kuipers 2009: 220). What actually triggers these symbolic boundaries is not well explored in the literature, however.

(Hale 2018: 39)

That is why this paper aims at exploring these boundaries in the communicative practice of advertising. Although a full discussion of this complex issue is beyond the scope of one article, looking at varying cultural perspectives can be a good starting point for further research.

\section{The cultural aspect of advertising - a cross-cultural comparison}

"The research on variation in humour is uneven. Some areas, such as gender differences, have attracted significant research, whereas other areas, such as ethnicity, age, class, national differences, etc. have seen considerably less work" (Attardo 2017). Thus, the paramount objective of this paper is to address cross-cultural differences in terms of ad appreciation and perceived humorousness; to this end, two distant cultures, that is, Polish and Taiwanese, were chosen to explore the impact of culture on the reception of advertising content in English.

It is important to note that "whether a humorous ad succeeds or fails is a function of many variables" (Gulas \& Weinberger 2006: 19), including audience factors, which are perhaps the most essential ones. They interact with both humour and product type, with the overall contextual situation, and with media placement as well, which testifies to the complexity of humour usage in advertising in general. Culture, in its broadest sense, usually determines whether something is funny or distasteful.

What is funny for the French may be anathema to an Arab; your very best story may be utterly incomprehensible to a Chinese; your most innocent anecdote may seriously offend a Turk. 
Cultural and religious differences may make it impossible for some people to laugh at the same time.

Apart from cultural differences, perception and appreciation of humour are also contingent on psychographic factors, for "something that is humorous to one individual may be offensive to another" (Gulas \& Weinberger 2006: 19); this is because of the fact that the humorous effect depends on the influence of individual perception as well, with personal taste, disposition or even willingness to process humour being likely to impact on the overall perceived funniness of the message. Yet, given the relatively small sample of research participants, the author decided not to focus on the psychographic measures in order not to obscure the study; instead, she chose to concentrate on the cultural aspect of controversial humorous ads.

\subsection{Research participants, objectives, and methodology}

As far as research participants are concerned, the author wanted to choose a culture that would be geographically and culturally distant from the Polish one, in the hope that the results would differ. Consequently, she has chosen Taiwanese culture, owing to the fact that she had access to this particular nation thanks to her friend on Taiwan who helped her to distribute the questionnaire. At this point, the author would like to gratefully acknowledge the contribution that Natasza Maria Olesiejuk from the National Taiwan Normal University made for this research to be conducted.

First, for the purpose of the Humour Research Project seminar (held in 2017 in Katowice under the patronage of the Institute of English, the Institute of English Cultures and Literatures, and the Institute of Romance Languages and Translation Studies of the University of Silesia, Poland), the author designed a questionnaire in Google Docs that was distributed to the students and graduates of the Institute of English and the Institute of English Cultures and Literatures of the University of Silesia, Poland, in October and November 2017. She managed to gather answers from 130 respondents altogether, 80 per cent of whom were females between 18 and 30 years of age. Then, in 2018, she asked her friend to help her to distribute the same questionnaire among Taiwanese informants. Thus, she managed to gather answers from 51 respondents altogether, 60 per cent of them females; 67 per cent of the informants were between 18 and 30 years of age while the remainder were in their 30s. Despite unequal gender representation, the results provided by male and female participants were not that different, which is why this variable was not taken into account in the study. Both groups consisted of very fluent speakers of the English language.

This study had a twofold objective:

1) to check ad appreciation of Taiwanese respondents based on a collection of press and internet multimodal advertising messages in English that were intended to be humorous;

2) to compare and contrast the results obtained from both Taiwanese and Polish respondents (described in detail in Stwora 2020) with the aim of finding trans-cultural similarities and differences in terms of ad appreciation.

To attain these goals, the research instrument in the form of an online survey in English was designed. Both Polish and Taiwanese research participants were supposed to fill it in and answer several questions concerning 15 multimodal ads intended to be humorous by the advertiser. As far as the rationale for the selection of ads for the study is concerned, the author aimed at choosing humorous multimodal ads that, in her opinion, were controversial and hence highly polarising acts of humour which were likely to border on distaste because of the imagery and themes featured (e.g. blood, sex, violence, etc.).

As regards the instrument adopted for the purpose of the research, the author used twostep written self-reports. Firstly, research participants were supposed to fill in self-reports on 
rating scales that aimed at checking their liking of each ad; they were requested to choose the "liking" or "disliking" option. In addition, they were asked whether they found the ads sampled inappropriate, offensive or disgusting. Subsequently, in order for the humour value to be checked, the respondents were asked to rate each ad on a Likert-type scale that ranged from very favourable, positive, and ambivalent, to a negative attitude; these were represented by the responses (4) very funny, (3) funny, (2) neutral, and (1) not funny, respectively. A short set of open-ended questions followed to check their comprehension and interpretations of the ads selected.

\subsection{Data presentation and discussion}

The results from the Taiwanese sample will be described in the lines below, whereas those obtained from Polish respondents were thoroughly described in the author's previous study (Stwora 2020).

\subsubsection{The ads liked by Taiwanese respondents}

The group of advertising messages liked by Taiwanese informants is composed of 5 commercial and 2 non-commercial ads (marked in red in Table 1). By way of clarification, non-commercial ads are concerned with the manipulation of social values and attitudes (Simões \& Freitas 2008: 5), whereas commercial ones are intended to sell us something and thus make profit.

Table 1. Taiwanese respondents' opinions concerning the ads rated as liked.

\begin{tabular}{|c|c|c|c|c|c|c|c|}
\hline & $\begin{array}{l}\text { Ad 1: } \\
\text { United } \\
\text { Colours of } \\
\text { Benetton } \\
\text { the textual: } \\
\text { - humorous } \\
\text { the visual: } \\
\text { + humorous }\end{array}$ & $\begin{array}{l}\text { Ad 2: } \\
\text { MASP Art } \\
\text { School } \\
\text { the textual: } \\
\text { - humorous } \\
\text { the visual: } \\
\text { + humorous }\end{array}$ & $\begin{array}{l}\text { the textual: } \\
\text { + humorous } \\
\text { the visual: } \\
\text { + humorous }\end{array}$ & $\begin{array}{l}\text { Ad 8: } \\
\text { Antonio } \\
\text { Federici } \\
\text { Ice Cream } \\
\text { the textual: } \\
\text { + humorous } \\
\text { the visual: - } \\
\text { humorous }\end{array}$ & $\begin{array}{l}\text { Ad 9: } \\
\text { United } \\
\text { Colours of } \\
\text { Benetton } \\
\text { the textual: } \\
\text { - humorous } \\
\text { the visual: } \\
\text { + humorous }\end{array}$ & $\begin{array}{l}\text { the textual: } \\
\text { - humorous } \\
\text { the visual: } \\
\text { + humorous }\end{array}$ & $\begin{array}{l}\text { the textual: } \\
\text { - humorous } \\
\text { the visual: } \\
\text { + humorous }\end{array}$ \\
\hline very funny & $0 \%$ & $7 \%$ & $40 \%$ & $15 \%$ & $10 \%$ & $42 \%$ & $21 \%$ \\
\hline funny & $29 \%$ & $29 \%$ & $20 \%$ & $35 \%$ & $42 \%$ & $26 \%$ & $31 \%$ \\
\hline neutral & $19 \%$ & $33 \%$ & $20 \%$ & $20 \%$ & $18 \%$ & $11 \%$ & $30 \%$ \\
\hline not funny & $52 \%$ & $30 \%$ & $20 \%$ & $30 \%$ & $30 \%$ & $21 \%$ & $18 \%$ \\
\hline
\end{tabular}

Let us begin with the theme of love and thus with two related ads for the United Colours of Benetton: Ad 1 shows a collage featuring the Pope and the Sheikh of the Al-Azhar Mosque kissing each other, whereas Ad 9 shows two other figures, namely Sarkozy and Merkel in exactly the same situation. As far as the first example is concerned, although the respondents said they liked the ad, they did not find it very amusing, as only about 30 per cent of them found it funny. Only 14 per cent considered the ad inappropriate because of the presence of religious leaders; others, on the other hand, stressed that it is the message they liked, namely that love is the true religion and that, regardless of skin colour, gender or religious beliefs, we all originated from and are united by love. They therefore recognised the intention of the advertiser to shock the audience and convey an important message that people of different 
religions should not hate one another and should "make love, not war." The same convention was used in Ad 9 with Sarkozy and Merkel but yielded different results, for the ad was rated as very funny or funny by the majority of the respondents. No one reported thinking that the ad was offensive or inappropriate (except the political leaders, perhaps), so what follows is that the image of kissing political leaders was found to be more amusing than the one of religious ones.

Next is Ad 2 for Brazil's Museu de Arte de São Paulo Art School that shows Vincent van Gogh dissected like a frog in a biology class; the very dissection is artistic in its nature, however, because the painter is dressed-up and his exposed intestines and internal organs are painted inside his body, which makes them resemble an impressionistic painting typical of van Gogh. Taiwanese informants liked the ad despite its presenting a dead artist and only 10 per cent of them thought it was inappropriate to show something like that in an ad and felt uncomfortable seeing internal organs, painted or not. Nevertheless, in spite of high liking, the results of funniness ratings were mixed (see Table 1). The group of respondents appreciated the original form of the ad, yet they had some problems with identifying the actual message behind the ad. Some of them said it was unclear and too abstract, while others drew such interpretations as: "your body and mind are the sources of many interesting ideas" or "art is a unique way of living, interpreting, and creating."

Another example is Ad 6 promoting Durex Extra Large condoms. It shows the photo of hit hurdles accompanied by the words "extra large." Both the textual and the visual layer are supposed to produce humorous exaggeration as they connote the idea of an extra large penis; notwithstanding an obvious sexual connotation, the ad was not judged as inappropriate whatsoever and received high ratings as far as humorousness is concerned. The ad was said to create a positive humorous image of the brand and to catch consumers' attention effectively. The same holds for Ad 12 for the National Health Service that rests on a visual metaphor and on the figure of replacement in which a penis is conceptualised as a half-smoked cigarette with the aim of discouraging men from smoking. The said advertisement was generally liked by 75 per cent of the respondents and negative feedback was very low (42 per cent of the informants said that the ad was very funny and 26 per cent that it was funny). Only 5 per cent of them were of the opinion that the ad could be considered rude or disgusting.

The penultimate ad to be described in this section is Ad 14 for One Life that encourages people to test for HIV. The image shows a couple kissing, but there are far more hands on the woman's back than there should be. The intention behind this ad is to show that she had many sexual partners before and may not be aware of having sexually transmitted diseases. 70 per cent of the respondents declared that they liked the ad and more than half rated it as funny, whereas 10 per cent stated that it contained an overly sexual image, which rendered the ad inappropriate.

The last ad in this section touches upon the issue of religious feelings. Ad 8, featuring Antonio Federici Ice Cream, portrays two probably gay priests who believe in salivation (instead of salvation) in anticipation of mouth-watering ice cream. High liking for the ad was declared by 60 per cent of the Taiwanese respondents; almost half of them thought the ad was funny, whereas 20 per cent were neutral and 30 per cent did not find it funny at all. A few informants ( 5 per cent, to be exact) said that using a reference to homosexual themes was inappropriate but the majority of research participants appreciated the ad's originality and the wordplay used.

\subsubsection{The ads disliked by Taiwanese respondents}

The group of ads disliked by Taiwanese participants comprised 6 commercial ads and 1 noncommercial one (marked in red in Table 2). 
Table 2. Taiwanese respondents' opinions concerning the ads rated as disliked.

\begin{tabular}{|c|c|c|c|c|c|c|c|}
\hline & \begin{tabular}{|l|} 
Ad 3: \\
Del Mar \\
Medical \\
Spa (cow) \\
the textual: \\
- humorous \\
the visual: \\
+ humorous \\
\end{tabular} & \begin{tabular}{l} 
Ad 4: \\
Del Mar \\
Medical \\
Spa \\
\multicolumn{1}{c|}{ (pig) } \\
the textual: \\
- humorous \\
the visual: \\
+ humorous
\end{tabular} & $\begin{array}{l}\text { the textual: } \\
\text { + humorous } \\
\text { the visual: } \\
\text { + humorous }\end{array}$ & $\begin{array}{l}\text { Ad 10: } \\
\text { Burger } \\
\text { King } \\
\\
\text { the textual: } \\
\text { + humorous } \\
\text { the visual: } \\
\text { + humorous } \\
\end{array}$ & $\begin{array}{l}\text { the textual: } \\
\text { - humorous } \\
\text { the visual: } \\
+ \text { humorous }\end{array}$ & $\begin{array}{l}\text { the textual: } \\
\text { + humorous } \\
\text { the visual: } \\
\text { + humorous }\end{array}$ & $\begin{array}{l}\text { the textual: } \\
\text { + humorous } \\
\text { the visual: } \\
\text { + humorous }\end{array}$ \\
\hline very funny & $0 \%$ & $20 \%$ & $5 \%$ & $5 \%$ & $5 \%$ & $5 \%$ & $5 \%$ \\
\hline funny & $30 \%$ & $35 \%$ & $50 \%$ & $40 \%$ & $15 \%$ & $10 \%$ & $37 \%$ \\
\hline neutral & $10 \%$ & $15 \%$ & $15 \%$ & $5 \%$ & $20 \%$ & $30 \%$ & $21 \%$ \\
\hline not funny & $60 \%$ & $30 \%$ & $30 \%$ & $50 \%$ & $60 \%$ & $55 \%$ & $37 \%$ \\
\hline
\end{tabular}

The first two ads by Del Mar Medical Spa present the audience with the drawing of a theory of evolution in which a woman evolves from a cow (Ad 3) and a man from a pig (Ad 4). Interestingly enough, the female version received more negative feedback and was perceived as ruder than the male one. 60 per cent of the respondents claimed that the female version was offensive while only 40 per cent found the male version inappropriate; what is more, the male version was also rated as more humorous, which may be due to the preponderance of women in the group of participants studied. The informants understood that the intention behind the ads was to show how a medical spa can turn an ugly beast into someone who resembles a human being. Yet, all in all, they did not appreciate it.

Another ad to be discussed here is a very controversial one featuring Humo condoms (Ad 5), in which a penis is likened to a beast. Taiwanese participants did not like it in general but considered it funny, for some appreciated the ad's creativity in terms of the comparison implied but were against explicit sexual content. Surprisingly, though, as many as 70 per cent of the respondents did not feel the ad was offensive. Conversely, Ad 10 for Burger King with covert sexual allusions made quite a stir, for it is literally referring to "blowing" in its rude meaning, which is why it had low liking; yet the results concerning its humorous value were mixed. 60 per cent of participants felt offended, which, again, can be attributed to the antifemale nature of the joke and the female-dominated group of informants. In a similar vein, humorous value turned out to be marginal for Ad 13, which shows a woman with an additional bust on her back, which is supposed to feature PlayStation Vita. This can be inferred from the small representation of a handheld game console with additional buttons. The body copy reads: "Touch both sides for added enjoyment." Only 15 per cent of the respondents declared they liked the ad, and the opinions concerning its offensive potential were mixed.

Next are the ads that make use of the themes of violence, blood, and death. For instance, Ad 11 for Dettol shows a blurred corpse in the background, one's hand covered in blood, and a line of Dettol products accompanied by a line: "When ordinary soap just won't do..." This ad featuring antibacterial products performed poorly, as 80 per cent of the informants did not like it at all; low funniness ratings stem from the fact that the participants were uncomfortable with the picture of blood and claimed they were not prepared for something like that to appear in an advertising message. Likewise, Ad 15 for the Centre of Consultancy for Road Victims (CCVR), which advocates cautious driving, was liked only by 40 per cent of the informants although almost half of them rated it as funny. Despite the image of Hitler's dead body flattened against a broken windscreen and accompanied by the line: "Well, it's not like that. Usually, the victim is an innocent," Taiwanese respondents did not like the ad because of excessive violence and the theme of death. They appreciated the message transmitted, however, saying it is good to remind people to drive safely. 
Additionally, mention should be made of one missing ad, namely Ad 7 for Antonio Federici Ice Cream (nun), which was skipped in the tables above due to mixed results in terms of ad appreciation. It emerges that Taiwanese respondents proved to be unsure of the ad itself and that humour value was very low, indeed. Although it was clear to the respondents that the image of a pregnant nun was to exaggerate the taste of ice cream and to attract people's attention, the answers "neutral" and "not funny" were more numerous than the positive ones. Interestingly enough, the example with a pregnant nun was considered less funny and was less appreciated than the other ad for Antonio Federici Ice Cream (Ad 8) with kissing priests.

\subsubsection{Polish versus Taiwanese perspective - survey results}

The comparative results for both Polish and Taiwanese surveys (marked with the letter $\mathrm{P}$ and $\mathrm{T}$, respectively) are very interesting. Given the cultural differences, it turns out that the perception of humorous yet controversial ads by Taiwanese respondents was different from the response from Polish participants. As one can see in Table 3, the plus sign (+) stands for the ads rated as liked, whereas the minus sign (-) for the prevalence of negative ratings. For the sake of conciseness, the author would like to focus solely on the examples in which major differences in the perception of ads were detected.

Table 3. Comparative results of both Polish (P) and Taiwanese (T) surveys. The plus sign (+) stands for the ads rated as liked, whereas the minus sign (-) stands for the prevalence of negative ratings.

\begin{tabular}{|l|l|l|l|l|l|l|l|l|l|l|l|l|l|l|l|}
\hline & Ad & Ad & Ad & Ad & Ad & Ad & Ad & Ad & Ad & Ad & Ad & Ad & Ad & Ad & Ad \\
& $\mathbf{1}$ & $\mathbf{2}$ & $\mathbf{3}$ & $\mathbf{4}$ & $\mathbf{5}$ & $\mathbf{6}$ & $\mathbf{7}$ & $\mathbf{8}$ & $\mathbf{9}$ & $\mathbf{1 0}$ & $\mathbf{1 1}$ & $\mathbf{1 2}$ & $\mathbf{1 3}$ & $\mathbf{1 4}$ & $\mathbf{1 5}$ \\
\hline $\mathbf{P}$ & - & + & - & - & - & + & - & - & - & - & + & + & + & + & + \\
\hline $\mathbf{T}$ & + & + & - & - & - & + & 0 & + & + & - & - & + & - & + & - \\
\hline
\end{tabular}

Ad 1, created to support the Unhate Foundation, shows a collage featuring the Pope and the Sheikh of the Al-Azhar Mosque kissing. While Polish respondents did not like the idea of showing religious leaders kissing, Taiwanese research participants had nothing against such a portrayal and rated the ad high in terms of ad appreciation. Polish participants felt far more offended at the picture due to the presence of religious leaders, whereas only 14 per cent of Taiwanese ones considered the ad inappropriate. In spite of the fact that Taiwanese respondents declared they liked the ad, its creativity, and the idea behind the picture, they did not find it very amusing.

To the author's mind, the example of Ad 7, featuring Antonio Federici Ice Cream and showing a sinful nun, was particularly thought-provoking. Polish respondents rated their appreciation of the ad very low: more than half of the informants declared dislike. The funniness rating was also very low because they were irritated that the advertiser was joking about religion. Taiwanese respondents, on the other hand, were unsure about the ad itself and the humour value was very low. In spite of the fact that they understood that the picture of a pregnant nun was intended to exaggerate the taste of ice cream and, most importantly, to catch the audience's attention, it turned out that positive responses to the ad in terms of its funniness were less numerous than the answers "neutral" and "not funny."

It seems important to mention that the other ad for Antonio Federici Ice Cream (Ad 8), showing kissing priests, was received well by the Taiwanese as compared to the one with a pregnant nun. And the situation was completely reversed with Polish informants. Poles were harsher when it came to the ad referring to homosexual themes and opposed to showing two probably gay priests who believe in salivation. 
Corresponding to the first example discussed, Ad 9 for the United Colours of Benetton and the Unhate Foundation shows Sarkozy and Merkel in exactly the same situation as the religious leaders beforehand; yet, their portrayal was not considered inappropriate by Polish participants (almost 70 per cent of them were fine with such a portrayal) despite the fact that the opinions as to ad appreciation were divided. Funniness ratings were roughly similar but the Taiwanese respondents were more numerous in rating the ad as very funny or funny; the advertisement was not considered offensive or inappropriate whatsoever.

Another major cross-cultural difference was detected when it comes to Ad 11 for Dettol, which promotes antibacterial products with the image of a blurred corpse in the background and the murderer's hand covered in blood. The majority of Taiwanese participants ( 80 per cent) stated that they did not like the ad and did not think it was funny, chiefly due to the fact that they were uncomfortable with the picture of blood. Conversely, Polish informants liked the ad very much - only 32 per cent of them had some reservations as far as the form of the ad was concerned, saying that there was no need to show a corpse in the background and the ad could have been subtler. Nonetheless, ad appreciation was very high, as opposed to the result obtained from the Taiwanese group.

A similar trend was present in Ad 13 that presents the audience with a picture of a woman with an additional bust on her back, which is supposed to stand for additional buttons on a handheld game console PlayStation Vita. The vast majority of Polish respondents declared they liked this ad, though ratings concerning funniness were mixed; what is more, Poles did not find the ad offensive but stressed the fact that the message was probably meant to be funny mostly to male audiences. In contrast, as few as 15 per cent of Taiwanese research participants responded positively to the ad. The humorous value turned out to be marginal while the results pertaining to the ad's offensive potential were mixed.

Lastly, Ad 15, for the Centre of Consultancy for Road Victims (CCVR), which advocates cautious driving with an unusual picture, i.e. that of Hitler's dead body flattened against a broken windscreen, was appreciated only by 40 per cent of Taiwanese research participants while almost half of them rated it as funny; this violent image was therefore found to render the ad dislikeable, although Taiwanese informants recognised the message behind the ad. Polish participants, on the other hand, said that they liked the ad very much: 80 per cent of the informants declared so in spite of the fact that 53 per cent rated it as not funny, probably because of the shockvertising strategy applied that renders the ad more serious, as it refers to one of the most pressing problems of developed societies. Hence, Poles appreciated the message transmitted and thus were more tolerant when it comes to the form, even though violence was present. But it can also be the case that they were simply more biased since, historically, Poles have many reasons to revile Nazis.

\section{Conclusion}

To conclude, it is important to stress that ad appreciation (that is, liking in terms of an ad's creativity, the way the message was transmitted, etc.) and the appreciation of humour value are two different things. One may appreciate the format, the colours, and the wittiness in an ad but may not find it amusing at all. This observation follows from this and the author's previous study (Stwora 2020), highlighting an important distinction to be kept in mind while conducting reception studies.

This article offered an overview of the answers of Taiwanese respondents as regards the corpus of selected multimodal advertisements that make use of debatable humour. Furthermore, it provided a comparative analysis of Polish and Taiwanese perspectives with the aim of finding trans-cultural similarities and differences in terms of ad comprehension and 
appreciation. Although it is impossible to delineate the border between the appealing and the appalling in contemporary advertising discourse, it seems that distant cultures can and do read the same humorous advertising message differently. On the whole, the study revealed that cultural programming is capable of dominating one's liking for an ad and perception of its humour value. It is not the author's intention to discuss the particularities of Polish or Taiwanese humour, for a full discussion of these complex topics is beyond the ambit of one paper. However, some interesting pieces of research on the issue of Taiwanese humour can be found in Liao (2001) or Chen (2016), while for detailed discussions about Polish humour, one could recommend Brzozowska \& Chłopicki (2012, 2014), for instance.

While the author would like to refrain from evaluations and generalisations, it seems that "culture hides more than it reveals, and strangely enough what it hides, it hides most effectively from its own participants" (Hall 1959: 39). While the uneven nature of data samples should be kept in mind, Poles taking part in the study turned out to be less tolerant when it came to such taboo topics as religion or homosexual issues than their Taiwanese counterparts. This may be accounted for in terms of their own religious beliefs, as Buddhist tradition seems far more tolerant when it comes to diversity and laughing at religion in general. It was demonstrated, for example, by Ott \& Schweizer (2018), that "religious background influences the threshold of what is considered offensive" (Ott \& Schweizer 2018: 12) and that, as compared to Asian religions, Christianity is far more hostile towards joking about religion, which results in reduced appreciation of such jokes. As they put it, "official Christianity's long-standing hostility to laughter has led to a religious climate of joylessness" (Ott \& Schweizer 2018: 13), which finds confirmation in the present study; Polish respondents, predominantly belonging to the Christian Catholic Church, did not appreciate the ads in which the theme of religion was used. It should be added that they did not mind implicit sexual themes but were against explicit depictions thereof. Moreover, they appreciated violent or even disgusting non-commercial ads even if they did not find them amusing because they considered such depictions appealing and thought-provoking.

Taiwanese participants, on the other hand, were repelled by such imagery and thus did not like either non-commercial or commercial ads if they contained any images of blood, violence or even implicit sexual themes. Also, the examples with implied death (Ad 11 for Dettol) and an explicit depiction of death (Ad 15 for CCVR) scored poorly, probably owing to the fact that the topic of death itself is traditionally avoided in the Chinese culture, for it constitutes a deepseated taboo (cf. Jacoby 2018). Whenever they detected sexual or hostile humour, they did not appreciate it, unlike their Polish counterparts. Taiwanese respondents had nothing against the ads referring to religion, perhaps because it was not their religion that was being laughed at. The situation could have been reversed if the study had been based on more Eastern ads and jokes about Taiwan and its local cultural taboos. All in all, the Taiwanese informants' perception of what is acceptable to show and what is not substantially differed from the Polish participants' perception, which testifies to the fact that there is a link between human cognitions and cultural differences. Consequently, in the light of this study, culture should be considered an intrinsic component of the human mind that is responsible for both perception and appreciation of humour.

What emerges from this cross-cultural analysis is that advertising is subject to cultural variation to a significant extent. "Apparently all cultures use humour" (Vuorela 2005: 15) but "humour is local and a sense of humour is usually highly context-specific, and is a form of cultural insider-knowledge" (Critchley 2002: 67), which means that humans and humour are not independent of cultures. It is the cultural and sociocultural aspect of human existence that provides the behavioural framework within which people happen to produce, process, and appreciate humour (Neuliep 2016; Michalik \& Sznicer 2017). That is why advertisers should be careful while designing ads to be shown all over the world, for culture conditions 
perception all the time and, much as we try, we can never escape that. It therefore seems suitable to close this paper with a very pertinent citation concerning the power of tabooness in advertising from Simões \& Freitas:

What makes this particular area so appealing as a subject for study is that it demonstrates beyond any doubt that taboo is not such a quaint, old-fashioned concept as might be expected from the more or less exotic and anthropological connotations of the word. Rather, it is something that is still very much present in contemporary society. Reflection on its occurrences - namely in advertising - can yield important clues as to the way society sees itself and is structured around divisions, classifications, restrictions, and separations (Douglas 1966). Issues such as dirtiness, sex, and some bodily functions, to name but a few, are still commonly referred to (...), which indicates the existence of a taboo subject.

(Simões \& Freitas 2008: 3)

Taboos remain present in everyday life and in everyday discourse, and "people today are still cautious when treading on issues that are usually considered dangerous" (Simões \& Freitas 2008: 197). Using tabooness in ads for humorous purposes is one thing. Knowing how to avoid setting off controversy by playing with humour and potential elicitors of disgust at the same time is another. The question of how to understand and predict failures better can only be answered by conducting similar pieces of research with more respondents, which seems a promising research path for the future.

\section{References}

Allan, K. \& Burridge, K. (2006). Forbidden Words: Taboo and the Censoring of Language. Cambridge: Cambridge University Press.

Attardo, S. (2017). Humor in Language. Oxford Research Encyclopedia of Linguistics. Retrieved July 10, 2018 from http://linguistics.oxfordre.com/view/10.1093/acrefore/9780199384655.001.0001/acrefore9780199384655-e-342.

Barsoux, J.L. (1993). Funny Business: Humour Management and Business Culture. London: Cassell.

Brzozowska, D. \& Chłopicki, W. (eds.) (2012). Polish Humour. Kraków: Tertium.

Brzozowska, D. \& Chłopicki, W. (eds.) (2014). Humor polski. Kraków: Tertium.

Bussmann, H. (1998). Routledge Dictionary of Language and Linguistics. London and New York: Routledge.

Chen, L. (2016). A Socio-Pragmatic Analysis of Taiwanese and Polish Humor: Casual Conversations and Television Variety Shows. Unpublished doctoral dissertation, Department of Pragmatics, The University of Łódź, Poland.

Critchley, S. (2002). On Humour. Thinking in Action. London: Routledge.

Davies, C. (2008). 'The Danish cartoons, the Muslims, and the new battle of Jutland', in: Lewis, P., Davies, J.C.H., Kuipers, G., Martin, R.A., Oring, E. \& Raskin, V. (eds.), 'The Muhammad cartoons and humour research: A collection of essays'. Humor: International Journal of Humor Research 21 (1), pp. 2-7.

Dynel, M. (2013). 'Humorous phenomena in dramatic discourse'. The European Journal of Humor Research 1, pp. 22-60.

Gulas, C.S. \& Weinberger, M.G. (2006). Humor in Advertising. Armonk, New York, and London: M.E. Sharpe.

Haidt, J. (2013). The Righteous Mind: Why Good People Are Divided by Politics and Religion. London: Penguin Books. 
Hale, A. (2018). 'I get it, but it's just not funny': Why humour fails, after all is said and done'. European Journal of Humour Research 6 (1), pp. 36-61.

Hall, E.T. (1959). The Silent Language. Greenwich, CT: Fawcett.

Hemenover, S.H., \& Schimmack, U. (2007). 'That's disgusting! ..., but very amusing: Mixed feelings of amusement and disgust'. Cognition \& Emotion 21 (5), pp. 1102-1113.

Hilliard, R.L. (2014). Writing for Television, Radio, and New Media. Boston: Cengage Learning.

Hurley, M.M., Dennett, D.C. \& Adams Jr., R.B. (2011). Inside Jokes. Using Humor to Reverse-Engineer the Mind. Cambridge, MA and London: The MIT Press.

Jacoby, M. (2018). Chiny bez makijażu. Warszawa: Warszawskie Wydawnictwo Literackie MUZA SA.

Jajszczok, J. (2019). 'Hideous or hilarious? The fine line between disgust and humour'. Paper presented at the conference Humor Research Project, University of Silesia in Katowice, April 4, 2019.

Korsmeyer, C. (2008). 'Fear and disgust: the sublime and the sublate'. Revue internationale de philosophie 246, pp. 367-379. Retrieved April 10, 2020 from https://www.cairn.info/revue-internationale-de-philosophie-2008-4-page-367.htm\#.

Krikmann, A. (2009). 'On the similarity and distinguishability of humour and figurative speech'. Trames 13 (63/58) (1), pp. 14-40.

Kuipers, G. (2009). 'Humour styles and symbolic boundaries'. Journal of Literary Theory 3 (2), pp. 219-239.

Kyratzis, S. (2003). 'Laughing metaphorically: metaphor and humour in discourse', paper presented during the $8^{\text {th }}$ International Cognitive Linguistics Conference held on July 2025, 2003 at the University of La Rioja, Spain. Retrieved March 18, 2018 from http://citeseerx.ist.psu.edu/viewdoc/download?doi=10.1.1.132.9689\&rep=rep1\&type=pdf.

Lewis, R. (2006). When Cultures Collide. Leading Across Cultures. Boston/London: Nicolas Brealey Publishing.

Liao, C.C. (2001). Taiwanese Perceptions of Humor: A Sociolinguistic Perspective. Taipei: Crane.

Matusz, Ł. (2017). 'Taboos and swearing: cross-linguistic universalities' in: Gabryś-Barker, D., Gałajda, D., Wojtaszek, A. \& Zakrajewski, P. (eds.), Multiculturalism, Multilingualism and the Self: Studies in Linguistics and Language Learning, Berlin: Springer, pp. 33-47.

Michalik, U. \& Sznicer, I. (2017). 'The use of humor in the multicultural working environment' in: Gabryś-Barker, D., Gałajda, D., Wojtaszek, A. \& Zakrajewski, P. (eds.), Multiculturalism, Multilingualism and the Self: Studies in Linguistics and Language Learning, Berlin: Springer, pp. 19-32.

Mohr, M. (2013). Holy Sh*t: A Brief History of Swearing. Oxford: Oxford University Press.

Morreall, J. (1983). Taking Laughter Seriously. New York: State University of New York Press Press.

Neuliep, J.W. (2016). Intercultural Communication: A Contextual Approach. Thousand Oaks: SAGE Publications.

Ott, K.H. \& Schweizer, B. (2018). 'Does religion shape people's sense of humour? A comparative study of humour appreciation among members of different religions and nonbelievers'. European Journal of Humour Research 6 (1), pp. 12-35.

Oxford Dictionaries online. Infotainment | Meaning of Infotainment by Lexico. Retrieved April 10, 2020 from https://www.lexico.com/definition/infotainment.

Palmer, J. (2004). Taking Humour Seriously. London: Routledge. 
Pérez-Sobrino, P. (2016). 'Shockvertising': conceptual interaction patterns as constraints on advertising creativity'. Círculo de Lingüística Aplicada a la Comunicación 65, pp. 257290.

Pérez-Sobrino, P. (2017). Multimodal Metaphor and Metonymy in Advertising. Amsterdam and Philadelphia: John Benjamins Publishing.

Sabri, O. (2012). 'Taboo advertising: Can humour help to attract attention and enhance recall?'. Journal of Marketing Theory and Practice 20 (4), pp. 407-422.

Simões, E. \& Freitas, L. (2008). Taboo in Advertising. Amsterdam and Philadelphia: John Benjamins Publishing Company.

Staley, R. \& Derks, P. (1995). 'Structural incongruity and humor appreciation'. Humor: International Journal of Humor Research 8 (2), pp. 97-134.

Stwora, A. (2020). 'The thin invisible line - between funny and distasteful multimodal advertising discourse' in: Kuczok, M., Stwora, A. \& Świerkot, M. (eds.), Explorations in Humor Studies: Humor Research Project, Newcastle upon Tyne: Cambridge Scholars Publishing, pp. 129-151.

Stwora, A. \& Zemełka, G. (2020). 'Towards enhancement, distraction or oblivion - studying the impact of humorous language in advertising' in: Kuczok, M., Stwora, A. \& Świerkot, M. (eds.), Explorations in Humor Studies: Humor Research Project, Newcastle upon Tyne: Cambridge Scholars Publishing, pp. 152-175.

Tsakona, V. (2017). 'Humor research and humor reception: Far away, so close' in: Chłopicki W. \& Brzozowska, D. (eds.), Humorous Discourse, Boston and Berlin: Walter de Gruyter Inc, 179-201.

Vuorela, T. (2005). Approaches to a Business Negotiation Case Study: Teamwork, humour and teaching. Helsinki: Helsinki School of Economics Print.

Yus, F. (2016). Humour and Relevance. Amsterdam and Philadelphia: John Benjamins Publishing Company.

\section{Advertising Material Used}

Ad 1: United Colours of Benetton. Benetton \& Unhate, Germany-France. Retrieved August 12 , 2017

from https://www.adsoftheworld.com/media/print/benetton_unhate_germanyfrance.

Ad 2: MASP Art School. Retrieved August 11, 2017 from https://www.adsoftheworld.com/media/print/masp_dissected_van_gogh.

Ad 3: Del Mar Medical Spa (cow). Retrieved August 12, 2017 from https://www.adsoftheworld.com/media/print/del_mar_cow.

Ad 4: Del Mar Medical Spa (pig). Retrieved August 12, 2017 from https://www.adsoftheworld.com/media/print/del_mar_pig.

Ad 5: Humo. Retrieved August 12, 2017 from https://jezebel.com/these-condom-ads-willhaunt-you-nsfw-5597541.

Ad 6: $\quad$ Durex. $\quad$ Retrieved August 12, 2017 from https://www.adsoftheworld.com/media/print/hurdles.

Ad 7: Antonio Federici Ice Cream (nun). Immaculately Conceived. Retrieved August 12, 2017 from https://www.adsoftheworld.com/media/print/antonio_federici_immaculately_conceived.

Ad 8: Antonio Federici Ice Cream (priests). We Believe In Salivation. Retrieved August 12, 2017

from https://www.adsoftheworld.com/media/print/antonio_federici_we_believe_in_salivation. 
Ad 9: United Colours of Benetton. Benetton \& Unhate, Vatican-Al Azhar. Retrieved August 12 , 2017

from https://www.adsoftheworld.com/media/print/benetton_unhate_vaticanal_azhar.

Ad 10: Burger King. Retrieved August 11, 2017 from https://www.adweek.com/creativity/unwitting-star-burger-kings-blow-job-ad-finallylashes-out-company-159347/.

Ad 11: Dettol. Retrieved August 11, 2017 from http://persuasion-andinfluence.blogspot.com/2015/02/calling-allmurderers.html.

Ad 12: NHS. $\quad$ Retrieved September 20, 2017 from https://pl.pinterest.com/pin/318418636127606706.

Ad 13: PSVita. Retrieved August 11, 2017 from https://www.adsoftheworld.com/media/print/playstation_touch_both_sides.

Ad 14: One Life. Retrieved September 20, 2017 from https://www.adsoftheworld.com/media/print/one_life_couch.

Ad 15: CCVR. Retrieved September 20, 2017 from https://www.adsoftheworld.com/media/print/ccvr_road_hitler. 